\title{
Ecological Divergence, Adaptive Diversification, and the Evolution of Social Signaling Traits: An Empirical Study in Arid Australian Lizards
}

\author{
Danielle L. Edwards, ${ }^{1, *}$ Jane Melville, ${ }^{2}$ Leo Joseph, ${ }^{3}$ and J. Scott Keogh ${ }^{4}$ \\ 1. School of Natural Sciences, University of California, Merced, California 95343; 2. Department of Sciences, Museum Victoria, Melbourne, \\ Victoria 3000, Australia; 3. Australian National Wildlife Collection, Commonwealth Scientific and Industrial Research Organisation \\ (CSIRO) Sustainable Ecosystems, Canberra, Australian Capital Territory 2601, Australia; 4. Research School of Biology, Australian National \\ University, Canberra, Australian Capital Territory 0200, Australia
}

Submitted December 16, 2014; Accepted June 11, 2015; Electronically published October 16, 2015

Online enhancement: supplementary PDF. Dryad data: http://dx.doi.org/10.5061/dryad.7nm09.

\begin{abstract}
AвsтRACт: Species diversification often results from divergent evolution of ecological or social signaling traits. Theoretically, a combination of the two may promote speciation, however, empirical examples studying how social signal and ecological divergence might be involved in diversification are rare in general and typically do not consider range overlap as a contributing factor. We show that ecologically distinct lineages within the Australian sand dragon species complex (including Ctenophorus maculatus, Ctenophorus fordi, and Ctenophorus femoralis) have diversified recently, diverging in ecologically relevant and social signaling phenotypic traits as arid habitats expanded and differentiated. Diversification has resulted in repeated and independent invasion of distinct habitat types, driving convergent evolution of similar phenotypes. Our results suggest that parapatry facilitates diversification in visual signals through reinforcement as a hybridization-avoidance mechanism. We show that particularly striking variation in visual social signaling traits is better explained by the extent of lineage parapatry relative to ecological or phylogenetic divergence, suggesting that these traits reinforce divergence among lineages initiated by ecologically adaptive evolution. This study provides a rare empirical example of a repeated, intricate relationship between ecological and social signal evolution during diversification driven by ecological divergence and the evolution of new habitats, thereby supporting emergent theories regarding the importance of both ecological and social trait evolution throughout speciation.
\end{abstract}

Keywords: agamid, aridification, Ctenophorus, diversification, ecological adaptation, social signal evolution.

\section{Introduction}

Rapid species diversification has been attributed to a few key causes, including selection on ecologically relevant traits (Grant and Grant 2008; Gavrilets and Losos 2009; Schluter

* Corresponding author; e-mail: dedwards5@ucmerced.edu.

Am. Nat. 2015. Vol. 186, pp. E144-E161. (C) 2015 by The University of Chicago. 0003-0147/2015/18606-55947\$15.00. All rights reserved.

DOI: $10.1086 / 683658$
2009) and evolution of social signaling traits, which are involved in inter- and intraspecific interactions (Masta and Maddison 2002; Mendelson and Shaw 2005; Maia et al. 2013). However, singular forms of selection may not be able to drive speciation to completion (Nosil et al. 2009; Servedio and Bürger 2014). While recent empirical studies suggest that both social signal and ecologically adaptive evolution might be important in diversification (Arnegard et al. 2010; Carlson et al. 2011; Wagner et al. 2012), these two processes are generally considered in isolation (e.g., Maan and Seehausen 2011), and studies explicitly accounting for range overlap are rare (Scordato et al. 2014). Consequently, there are few empirical studies exploring how both ecologically adaptive and social signal evolution contribute to diversification (Maan and Seehausen 2011). Thus, the combined importance of these factors remains unclear, especially when accounting for geographical context (Scordato et al. 2014).

The effects of ecological factors on the evolution of social signaling traits are potentially multifaceted (Safran et al. 2013). Reinforcement may drive social signal and preference evolution to limit hybridization, representing sexual selection for good genes (Hoskin and Higgie 2010; Maan and Seehausen 2011). Selection against hybridization may accelerate speciation in sympatry or parapatry (WestEberhard 1983; Butlin 1987; Gavrilets 2004), particularly between ecologically distinct taxa (Nosil et al. 2009). Ecological divergence may also stimulate evolution of social signals in different environments for maximal perception/ transmission (e.g., sensory drive; Endler and Basolo 1998; Boughman 2002) by modifying signal design and sensory properties (Boughman 2001; Seehausen et al. 2008) or by impacting mate preferences (Maan and Seehausen 2011). Furthermore, some form of divergent ecological selection 
on sexually selected traits may be required for speciation to be driven by sexual selection (Servedio and Bürger 2014).

Ecological adaptation and social signal evolution have been independently inferred as having driven the diversification of the species-rich amphibolurine lizard radiation in Australia (family Agamidae). Adaptive diversification has been suggested for many lizard taxa, including amphibolurines, as indicated by rapid body size evolution (Harmon et al. 2003), and, more specifically, in the amphibolurine genus Ctenophorus, through association between ecomorphological traits and fitness in different habitats (Melville et al. 2001). Alternatively, Stuart-Fox and Owens (2003) argued that sexual selection, resulting in diverse visual social signals, better predicts species richness in amphibolurines and thus underlies their diversification. Evidence of this is observed in the Ctenophorus genus, where limited gene flow is observed between incipient species with divergent visual social signals (McLean et al. 2014). However, the processes driving species diversification in amphibolurines may be far more complex.

Studies of phenotypic trait evolution have largely been used to investigate the processes driving diversification, and these can be grouped into two categories-those related to fitness and those used for social signaling. Yet, distinctions between these two trait categories may not be so simple. Ecomorphological trait evolution in lizards is seen as purely linked to fitness (Losos 1990; Melville et al. 2001; Wollenberg et al. 2013). The evolution of dorsal marking traits, often considered to be driven by ecological selection for crypsis against predators (Stuart-Fox and Owens 2003; Rosenblum 2006), may also be influenced by sexual selection for dimorphic coloration (Chen et al. 2012). Social signaling traits (i.e., visual color and chemical signal traits) are associated with mate choice (i.e., female preferences), interspecific interactions (i.e., male territory marking), or both (Endler 1992, 1993), and so their evolution is almost always inferred as being driven by sexual selection. The evolution of visual signaling traits (i.e., chest/throat patch pattern, shape, and extent), used in signaling to mates or conspecific males through heador chest-raising behaviors, are putatively under sexual selection in amphibolurine agamids (Ord and Stuart-Fox 2006; Chen et al. 2013) but in other lizards have been shown to be influenced by ecological factors (Robertson and Rosenblum 2009). Chemical signaling traits here are secondary sexual traits consisting of pores around the cloaca and extending down the ventral surface of the legs (femoral and preanal pores) that deposit volatile chemical cues associated with mate choice and/or are intraspecific through territorialmarking behaviors in lizards (Cooper 1994). These traits are not necessarily indicative of the chemical composition of such signals. Nevertheless, evolution of the structures that deliver chemical cues could thus be subject to either sexual selection (as driven by mate choice for greater numbers of pores reflecting dominance or species status) or ecological selection (as driven by more optimal delivery of cues in different ecological contexts), with stronger support for the latter in lizards specifically (Alberts 1992; Iraeta et al. 2011).

Therefore, studying the evolution of combinations of a range of phenotypic and ecological traits offers opportunities to distinguish whether social signal, adaptive evolution, or both can explain species diversification (Scordato et al. 2014). To empirically characterize the relationship between ecological divergence and social signal evolution, we explore the evolution of ecologically linked traits (i.e., ecomorphological and dorsal markings) and social signaling traits (i.e., visual and chemical signaling) in relation to ecological diversification in a closely related subgroup of amphibolurine agamid lizards, the Ctenophorus maculatus species complex (also including Ctenophorus fordi and Ctenophorus femoralis; fig. 1). Lineages within this species complex, commonly referred to as sand dragons, occupy a range of coastal and inland sand dune and plain regions, representing shrubland, mallee woodland, and spinifex grass habitats (Wilson and Swan 2008). These shortlived lizards (life span is 1 to several years; Henle 1991) comprise 11 parapatric/allopatric lineages and occupy some of the most recently derived arid sand habitats in Australia (Fujioka et al. 2009; Fujioka and Chappell 2010; Hesse 2010; fig. 1). Species display phenotypic differences typically associated with adaptive evolution, namely, divergence in background coloration and pattern as well as body shape (fig. 1). While it is thought that there is no female choice in some sand dragons (i.e., presence/absence of blue head color in C. fordi; Olsson 2001), traits typically associated with visual social signaling in lizards (i.e., markings on the throat and chest; Stuart-Fox and Ord 2004; fig. 1) vary considerably between lineages and may function in species recognition. Furthermore, femoral and preanal pore traits that release volatile chemical signals (termed chemical social signaling traits; see above; not shown in fig. 1) also vary considerably between lineages.

Given the recent origin of arid habitats in Australia and the striking variation in ecologically linked traits in the $C$. maculatus species complex (fig. 1), we predict that ongoing adaptive divergence to diversifying habitats has led to a significantly greater degree of subclade disparity in ecomorphological traits-indicative of widespread convergent adaptive evolution-than expected under random diversification (e.g., Brownian motion). Such niche expansion might also be expected to drive diversification in sexual signaling traits. However, considering significant parapatry in many lineages (fig. 1), we predict that ecologically driven evolution alone is unlikely to explain the dramatic variation in social signaling traits, particularly visual signaling traits, but that interspecific interactions mediated by spatial overlap also explain social signaling divergence. We test these 


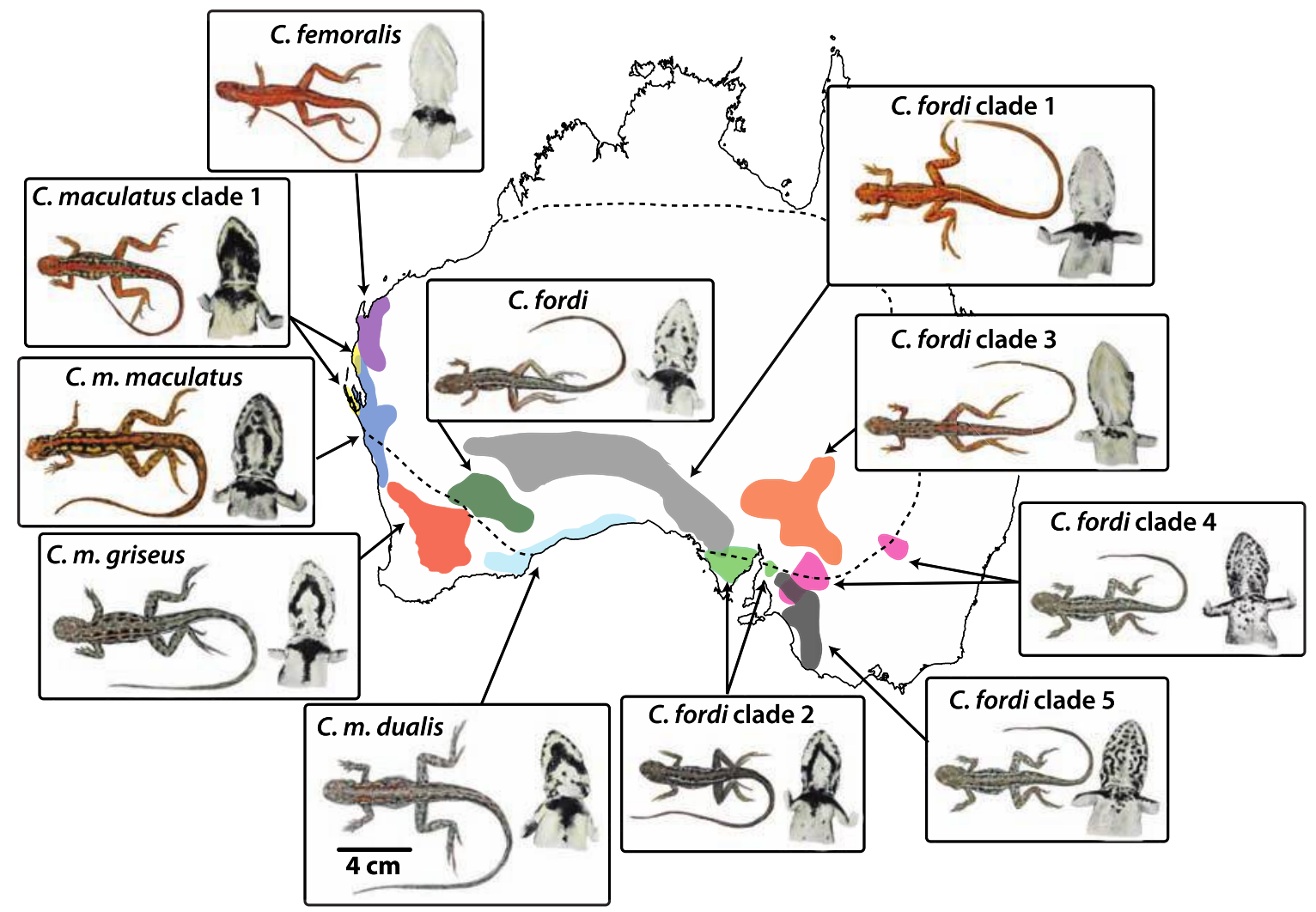

Figure 1: Distribution of lineages within the Ctenophorus maculatus species complex, including drawings of the dorsal surface (showing body proportions and dorsal markings) and visual social signals (i.e., ventral throat and chest pattern). Dorsal drawings are scaled to mean male snout-vent length (see C. m. dualis for scale bar). Extent of the arid zone is also shown (dotted line). Illustrations by Corrine Edwards.

hypotheses using integrative approaches drawing from ecological, genetic, and phenotypic lines of enquiry. Our study represents a rare empirical exploration of how the evolution of traits associated with fitness and social signaling relate to ecological diversification and geographic context in a recently derived biome, the arid zone of Australia.

\section{Methods}

\section{Sampling and Data}

Sampling strategy and specimens. We sampled 153 individuals (fig. S1; table S1; figs. S1-S16 and tables S1-S12 available online) from 11 lineages in the Ctenophorus maculatus species complex from the Australian Museum, South Australian Museum (Australian National Biological Tissue Collection), Western Australian Museum, Museum Victoria, and the Australian National Wildlife Collection (Commonwealth Scientific and Industrial Research Organisation [CSIRO]). Samples cover the geographic, morphological, genetic, and ecological variation encompassed by the group (fig. S1; table S1) and were informed from distribution-wide $m t D N A$ screening (see data deposited in the Dryad Digital Repository: http://dx.doi.org/10.5061/dryad.7nm09 [Edwards et al. 2015]). Coalescent species delimitation approaches (Edwards and Knowles 2014; fig. S2) and morphological distinction among lineages (figs. S3, S4; tables S2-S4) support the evolutionary distinction of lineages.

Genetic data. Multilocus genetic data were collected for six loci, including two $m t D N A$ loci $(N D 2,16 S)$ and four nuclear loci (PRLR, BACH1, NTF3, GAPD; table S5) using the methods outlined in Edwards et al. (2007, 2012). Allelic states for nuclear genetic data were resolved using PHASE (Scheet and Stephens 2006).

Environmental data. Environmental variables (table S6) were derived from publicly available climate (WorldClim, http://www.worldclim.org; Hijmans et al. 2005), vegetation (NASA-MODIS/Terra data set, http://modis.gsfc.nasa.gov /data/dataprod/), and soil (Australian Soil Information System, http://www.asris.csiro.au/) data. Specific treatment of these variables is outlined below.

Phenotypic data. Morphological data (table 1) were collected where possible (81 males and 43 females), including ecologically relevant and social signaling characters. Con- 
tinuous variables were log transformed prior to analysis. Continuous morphometric characters were corrected for allometric shape using the equation specified in Lleonart et al. (2000). Scale count variables were regressed against body size (i.e., snout-vent length), with the residuals used in subsequent analyses. Male and female data were analyzed separately due to sexual dimorphism in several continuous characters (detected using regression comparisons between male and female data; results not shown).

\section{Phylogenetic Relationships and Timing of Divergence}

We jointly estimated the evolutionary relationships and timing of divergence among lineages within the C. maculatus species complex to determine how the phylogenetic divergence of lineages relates to the evolution of sand habitats within Australia using *BEAST (Heled and Drummond 2010). Species divergences were estimated using the calibration method outlined in McCormack et al. (2011), as no internal fossil calibrations exist for the C. maculatus species group. We estimated the mean rate of evolution ND2 using a BEAST (Drummond and Rambaut 2007) analysis across the Agamidae family, using Leiolepis belliana as an outgroup. BEAST analyses were run for 15 million generations with a $10 \%$ burn-in and utilized two fossil calibrations previously used for divergence dating in amphibolurine lizards (for settings, see Edwards and Melville 2011), namely, a Pliocene phrynocephaline fossil (Zerova and Chkhikvadze 1984) and a Miocene amphibolurine fossil (Covacevich et al. 1990). Log files were checked for stationarity using Tracer v1.5 (Rambaut and Drummond 2007), and high effective sample size (ESS) values were confirmed. Tree files were summarized using TreeAnnotator, version 1.7.4 (Drummond and Rambaut 2007), showing congruent divergence dates (fig. S5) with previous analyses for amphibolurine agamids (Hugall et al. 2008).

A mean rate of 0.013 (fig. S5) for ND2 was fixed in species tree analyses under a strict clock model (McCormack et al. 2011) using multilocus genetic data in *BEAST (Heled and Drummond 2010). Analyses were run for three independent iterations of 100 million generations, sampling every 1,000 with a $10 \%$ burn-in. Tree files were combined after convergence (i.e., high ESS values using Tracer v1.5; Rambaut and Drummond 2007), and topological congruence was confirmed. The median time-calibrated species tree was then used in all further comparative analyses, along with 1,000 trees sampled from the posterior distribution where appropriate.

\section{Patterns of Niche Divergence through Time}

Tests of niche divergence were used to assess changes in niche space in a phylogenetic context using a modified version of the multivariate niche comparison approach developed by McCormack et al. (2010). Lineage occurrences (see appendix) were used to extract environmental data to calculate environmental differences between paired lineage comparisons relative to the background environmental differences, to determine whether niches between compared lineages were conserved or divergent. Environmental variation was first reduced to relevant niche axes using the dudi .pca R function of the ade4 package (Dray and Dufour 2007). Biological interpretations were drawn from the most heavily loaded variables in each niche axis (McCormack et al. 2010), with the majority of environmental variance (>90\% overall variance) consistently described in 10 principal component (PC) axes (table S7). We limit our interpretation to axes both explaining a modest proportion of variation $(>3 \%)$ and having clear biological interpretations (McCormack et al. 2010).

Significance of pairwise tests was determined by calculating the difference between observed niche overlap $\left(D_{\mathrm{obs}}\right)$ between lineages relative to the null distribution (background) of niche overlap ( $\left.D_{\text {null }}\right)$ between lineages on each niche axis. Divergence between lineage niches was inferred when $D_{\text {obs }}>D_{\text {null, }}$, while niche conservation was inferred when $D_{\text {obs }}<D_{\text {null }}$. Significance of this test was determined using two criteria: (a) $D_{\text {obs }}$ was outside the $95 \%$ confidence limits of $D_{\text {null }}$ and $(b)$ paired $t$-tests showed significant differences between $D_{\text {obs }}$ in paired lineage comparisons (niche divergence only; McCormack et al. 2010). In setting up comparisons, our goal was to determine the predominant patterns of niche divergence/conservation at each node in the median phylogeny (fig. 2). Therefore, we tested all possible sister-group comparisons among extant lineages. Significance of paired $t$-tests was corrected using Bonferroni correction for multiple comparisons. Patterns of niche divergence/conservation were considered predominant if $75 \%$ or more of the comparisons at each node showed the same pattern.

\section{Trait Data for Characterizing Ecological and Phenotypic Evolution}

Each data set underwent variable reduction prior to further analyses. Continuous trait sets (climate, vegetation, soil, and ecomorphology) were reduced using the dudi.pca $\mathrm{R}$ function of the vegan package (Oksanen et al. 2013). Trait sets containing only categorical data (visual signaling and dorsal markings) were reduced using correspondence analysis undertaken using the MCA $\mathrm{R}$ function of the FactoMineR package (Husson et al. 2013). For trait sets with both continuous and categorical data (chemical signaling), the dudi.mix $\mathrm{R}$ function from the vegan package (Oksanen et al. 2013) was used to reduce the data set. Given the potential for differences in the diversification of line- 
Table 1: Morphological characters collected within each trait set for the Ctenophorus maculatus species complex and a description of how characters were measured

\begin{tabular}{|c|c|c|}
\hline Character set, character & Description of measurement & Units/categories \\
\hline \multicolumn{3}{|l|}{ Ecomorphological characters: } \\
\hline Snout-vent length (SVL) & Distance between tip of nose and cloaca & $\mathrm{mm}$ \\
\hline Axillo-groin length (AG) & $\begin{array}{l}\text { Distance between posterior of forelimbs and } \\
\text { anterior of hind limbs }\end{array}$ & $\mathrm{mm}$ \\
\hline Arm length (AL) & $\begin{array}{l}\text { Length of arm from tip of claw on fourth } \\
\text { digit to where arm joins body }\end{array}$ & $\mathrm{mm}$ \\
\hline Finger length (FiL) & $\begin{array}{l}\text { Distance between metacarpal and tip of claw } \\
\text { on fourth digit of hand }\end{array}$ & $\mathrm{mm}$ \\
\hline Toe length (ToL) & $\begin{array}{l}\text { Distance between metatarsal and tip of claw } \\
\text { on fourth digit of foot }\end{array}$ & $\mathrm{mm}$ \\
\hline Leg length (LL) & $\begin{array}{l}\text { Length of leg from tip of claw on fourth digit } \\
\text { to where leg joins body }\end{array}$ & $\mathrm{mm}$ \\
\hline Tail length (TL) & Length of tail from tip to cloaca & $\mathrm{mm}$ \\
\hline Fourth finger lamellae (FS) & No. lamellae on fourth digit of hand & Count \\
\hline Fourth toe lamellae (TS) & No. lamellae on fourth digit of foot & Count \\
\hline \multicolumn{3}{|l|}{ Chemical signaling characters: } \\
\hline Femoral pores (Pores) & $\begin{array}{l}\text { Avg. no. femoral pores (averaged across left } \\
\text { and right legs) }\end{array}$ & Count \\
\hline Femoral pore arrangement $(\mathrm{PArr})^{\mathrm{a}}$ & Extent of femoral pores along foreleg & Midleg/knee \\
\hline Femoral pore visibility (FPVis) $^{\mathrm{a}}$ & Visibility/obviousness of femoral pores & Yes/no/weakly \\
\hline \multicolumn{3}{|l|}{ Dorsal marking characters: } \\
\hline Paravertebral lines (PVL) & Presence, clarity, and color of PVLs & Absent/indistinct/clear/black \\
\hline Paravertebral spots (PVSpots) & Presence and color of PVSs & Absent/white/black/black and white \\
\hline Dorsal background color (BGCol) & Predominant coloration on dorsal surface & $\begin{array}{l}\text { Gray-black/yellow-brown/orange- } \\
\text { brown/red-orange/brown-black }\end{array}$ \\
\hline \multicolumn{3}{|l|}{ Visual signaling characters: } \\
\hline Chest patch pattern $(\mathrm{CPPatt})^{\mathrm{a}}$ & Shape of chest patch & $\begin{array}{l}\text { None/block/diamond/spotted/ } \\
\text { mottled/mottled T }\end{array}$ \\
\hline Chest patch extent $(\mathrm{CPE})^{\mathrm{a}}$ & Extent of chest patch & None/arms (inc. chest)/chest only \\
\hline Throat markings $(\mathrm{TM})^{\mathrm{a}}$ & $\begin{array}{l}\text { Presence, clarity, and shape of male throat } \\
\text { markings }\end{array}$ & $\begin{array}{l}\text { Absent/unclear chevron/clear } \\
\text { chevron/mottled/lines }\end{array}$ \\
\hline
\end{tabular}

${ }^{a}$ Measured only in males.

ages climatic and structural (vegetation and soil) niche space, we chose to separate these elements in subsequent analyses. Environmental data were extracted from the individuals measured for phenotypic characters, and standardized variables were collected into three data sets: climate (15 Bioclim variables; table S6), vegetation, and soil.

\section{Ecological and Phenotypic Divergence through Time}

We used disparity-through-time (DTT) analyses to track the trajectory of observed relative subclade disparity in relation to a null distribution, whereby traits evolve under Brownian motion (BM), allowing interpretation of how average subclade disparity has changed through time (Harmon et al. 2003). High observed subclade disparity in relation to the null suggests trait variation within subclades, rather than between, which indicates subclades have diver- sified in trait space and lineages have evolved to fill similar regions of trait space (Harmon et al. 2003). Conversely, low observed subclade disparity compared to the null suggests trait variation is distributed between subclades with little trait diversification and no overlap among subclades in trait space (Harmon et al. 2003), which can indicate constrained evolution (Smith et al. 2011). Furthermore, changes in relative subclade disparity can suggest mechanisms of trait evolution. High relative subclade disparity followed by a decline toward the tips indicates an early burst of diversification that has typified adaptive radiation, while the opposite trend may suggest recent increasing rates of trait diversification (Harmon et al. 2003).

DTT analyses were undertaken using lineage means for axes describing $95 \%$ of the variation for each ecological and phenotypic trait set and the dtt function (geiger; Harmon et al. 2008) using the average squared Euclidean 


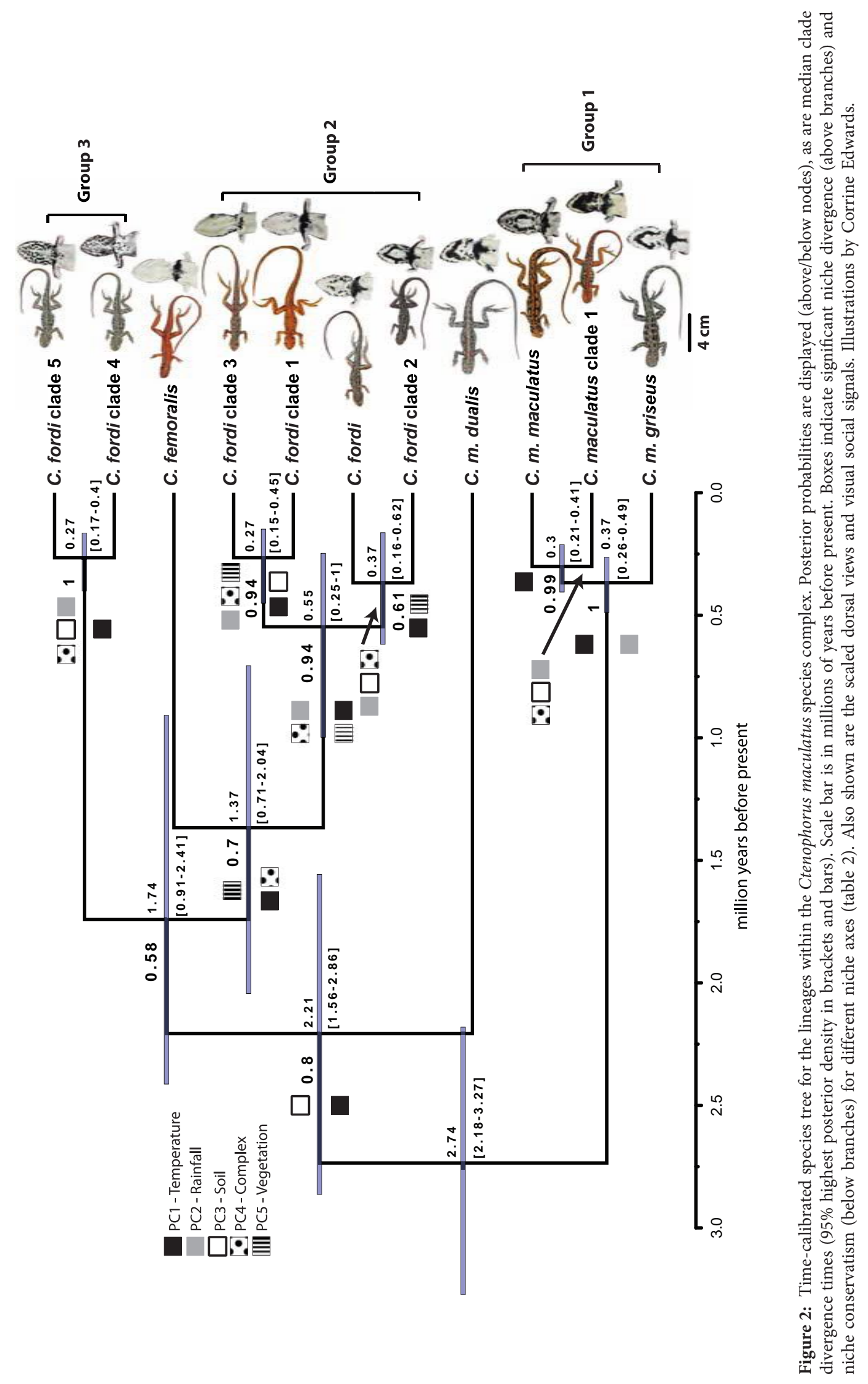

E149

This content downloaded from 150.203.051.207 on March 03, 2016 15:04:13 PM 
distance index. Given our small sample sizes, the impacts of measurement error are potentially large. However, we also note that other studies have used this technique to analyze patterns of trait evolution using similarly sized trees (e.g., Evans et al. 2009; Smith et al. 2011). To ensure our results were robust to variance in tip state, we created 20 data sets by randomly sampling one replicate specimen within each lineage. Each replicate data set was analyzed using the median species tree (fig. 2). For standard DTT analyses, we accounted for phylogenetic uncertainty and uncertainty in divergence times using a custom script to iterate DTT analyses across 1,000 trees from the posterior distribution, in addition to the median supported species tree (fig. 2). For each replicate tree, we calculated trait disparity under the null (BM model) using 1,000 simulations and compared this to the observed trait disparity. Interpretation of these analyses was based on plots of observed relative subclade disparity for each of 1,000 posterior trees and the median species tree (fig. 2). To represent the null distribution, we also plotted the 95\% confidence interval (CI) from 1,000 simulations from each of 1,000 posterior trees.

We further investigated the mode of ecological and phenotypic trait evolution by testing which model of trait evolution fits the first two axes of each trait set. We compared four relevant models: Brownian motion, OrnsteinUhlenbeck (OU), Pagel's delta (PD), and white noise (WN). Under BM, traits evolve along a random walk, whereas under OU, traits evolve toward a single optimum phenotype (Butler and King 2004). PD tests for fit to the AC/DC model of trait evolution (Blomberg et al. 2003; Harmon et al. 2010), where high values of delta predict trait diversification is concentrated toward the tips, while values $<1$ suggest trait evolution is consistent with an early burst model of evolution (Pagel 1999). Alternatively, support for a WN model would suggest traits across the phylogeny were drawn randomly from a normal distribution, suggesting a lack of phylogenetic signal (Hunt 2007). Model fits were undertaken using the fitContinuous function (geiger; Harmon et al. 2008). Considering our small sample sizes may lead to lack of power to differentiate models using corrected Akaike information criterion (AICc) comparisons, we undertook model choice using the likelihood ratio test approach implemented in the pmc R package (Boettiger et al. 2012) using 1,000 bootstrap replicates.

\section{The Relationship between Phenotypic and Ecological Evolution}

Evolutionary correlation between traits can suggest trait coevolution (Garland et al. 1992). Furthermore, such correlational tests can also measure the scale and direction of evolutionary change in one trait given the evolution of another (Pennell and Harmon 2013). For example, signifi- cant correlations between ecological and phenotypic traits typify ecologically driven phenotypic evolution (Garland et al. 1992; Glor 2010), which is expected in adaptive trait evolution. Furthermore, evolutionary correlations among phenotypic traits may suggest related functional roles (Garland et al. 1992) or, if traits are uncorrelated, may reflect divergent functional roles (Cheverud et al. 1989).

Tests for correlated evolution among phenotypic traits and between ecological and phenotypic traits were undertaken using phylogenetic independent contrasts (PIC). Ortho-normal contrasts were calculated for the major axes of variation (PC1 and PC2) of each trait using the pic.ortho function (ape; Paradis et al. 2004), which implements Felsenstein's (2008) method for incorporating intraspecific variance. Trait correlations were then tested using linear regression that force the intercept though the origin (Felsenstein 1985; Garland 1992), accounting for phylogenetic uncertainty by iterating analyses over 1,000 random trees from the posterior distribution. Significance was calculated from the mean correlation across trees relative to its standard error using a $t$-distribution with $n-2$ degrees of freedom, where $n$ equals the number of taxa. Phylogenetic correction was warranted (Revell 2010) in cases where phylogenetic signal in the regression residuals of all trait comparisons was estimated using the phylosig function (phytools; Revell 2012) and Blomberg's $K$ statistic (Blomberg et al. 2003). Significance of tests for phylogenetic signal was assessed using 1,000 replicates and incorporating intraspecific variation. To ensure type I errors and estimates of $R^{2}$ were not inflated by using phylogenetically corrected tests where not appropriate (i.e., no phylogenetic signal in residuals; Revell 2010), we estimated the relationship between traits without phylogenetic correction for those trait comparisons.

\section{The Relative Influence of Ecology and Spatial Overlap on Trait Variation}

Variation partitioning was used to distinguish between the ecological and spatial sources of variance in social signaling (visual and chemical) traits relative to male traits predominantly associated with fitness (i.e., dorsal markings). Only male fitness traits were used here as a direct comparison to those involved in social signaling. Variance partitioning treats explanatory variables as nonmutually exclusive contributors to variance in the response variable using redundancy analysis, calculating variance explained by each factor independently and in concert (Borcard et al. 1992). We tested the proportions of variation in phenotypic traits explained by environmental factors, phylogeny, and spatial distributional overlap in variance partitioning analyses. If phenotypic variation is predominantly explained by environmental factors, this supports the hypothesis that ecological 
divergence explains phenotypic evolution. Alternatively, if spatial overlap principally explains phenotypic variation, this supports the hypothesis that phenotypic divergence is better explained by parapatric/spatially proximate lineagesproviding evidence that social interactions between lineages promotes divergence in phenotypic traits.

Multivariate response variable data were lineage means across all phenotypic axes describing $~ 95 \%$ of the variation. Environmental variables were averaged lineage means across axes describing $95 \%$ of the variation in climate, vegetation, and soil niche traits. To calculate a biologically meaningful measure of spatial overlap, species distribution models (SDMs) were used to estimate lineage distributions using MaxEnt (see appendix for methodological details), applying a cutoff to distributions using the maximum training plus specificity threshold (Liu et al. 2005). Pairwise spatial overlap between lineages was calculated using custom scripts in $\mathrm{R}$ (in $\mathrm{km}^{2}$ ), and the results were log transformed prior to further analysis. To account for phylogenetic relationships, the median species tree was converted to patristic distances (fig. 2). We used the pcnm function (spacemakeR; Dray 2013) to convert distance matrices (spatial overlap and phylogeny) to multivariate data. To reduce colinearity of explanatory variables, we ran forward variable selection on multivariate trait sets, and significant axes were used in a variation partitioning analysis using the functions ordiR2step and varpart (vegan; Oksanen et al. 2013), respectively. Significance of fractions of interest was determined using the rda function (vegan; Oksanen et al. 2013).

\section{Results}

\section{Phylogenetic Relationships and Timing of Divergence}

The species tree shows rapid evolution of the Ctenophorus maculatus species group over the past $\sim 3$ million years (fig. 2). This analysis confirms that several named species are not monophyletic and provides good support for most relationships among lineages (see also Edwards and Knowles 2014). Major divergence events are dated between 1.5 million and 3 million years ago, the majority of speciation events between sister lineages occurring within the past 500,000 300,000 years. The relationships inferred suggest multiple invasions of the arid zone from more temperate regions, both recently (group 1) and deeper in the phylogeny, followed by rapid diversification (group 2). Additionally, there has been diversification of lineages into temperate regions from the arid zone (figs. 1, 2).

\section{Patterns of Niche Divergence through Time}

Principal component analyses (PCA) identified 10 axes explaining $91.97 \%$ of the observed environmental variance among lineages (table S7), however, we limited interpretation to the first 5 PC axes, given that these axes each explained $>3 \%$ variation and were biologically interpretable (McCormack et al. 2010; table S7). These five axes cumulatively explained $>70 \%$ of the observed environmental variation (table 2). Biological interpretations included temperature (PC1), precipitation (PC2), soil (PC3), and vegetation (PC5) variation, while PC4 included variation in a complex of elevation, soil, vegetation, and precipitation. Detailed results from comparisons among lineages are listed in table S8. Members of group 1 were divergent in thermal niche (PC1) and conserved in precipitation niche (PC2; table 2; fig. 2). Niche conservatism was apparent in thermal niche (PC1), while divergence in soil niche (PC3) was evident in comparisons between Ctenophorus maculatus dualis and members of groups 2, 3, and Ctenophorus femoralis. Comparisons between group 3 and C. femoralis + group 2 were inconclusive, while between $C$. femoralis and group 2 there was divergence in vegetation niche (PC5) and conservation of temperature (PC1) and complex (PC4) niches. Among lineages occupying the most arid regions (group 2 figs. 1,2 ), there was divergence in precipitation (PC2) and complex (PC4) niches but conservation in temperature (PC1) and vegetation (PC5) niches. There were no obvious trends in overall lineage comparisons.

\section{Ecological and Phenotypic Divergence through Time}

Most ( $>95 \%$ ) of the variance in phenotypic and ecological traits could be accounted for by 3-9 axes after data reduction (table S9). Despite our small sample sizes, we found limited evidence that this affects the patterns inferred from DTT analyses (figs. 3, S6). DTT plots show that phylogenetic uncertainty was limited to variation concentrated early in the phylogeny (fig. 3). In general, the difference between the null (Brownian motion) and observed subclade disparity increased toward the present in all phenotypic and ecological traits, indicating that lineages have diversified among subclades and have independently converged in trait space (Harmon et al. 2003). This trend was most strongly seen in the plots where average subclade disparity clearly exceeded the null, particularly toward the present, in visual and chemical social signaling, dorsal marking, and vegetative niche traits (fig. 3).

Analyses assessing trait evolution model fit (table 3) revealed AC/DC model (PD) best-fit axes PC1 and PC2 for climatic niche (fig. S7) and female ecomorphological traits (fig. S8). Values of delta $>1$ suggest that rates of trait diversification have increased toward the present for many traits and are thus consistent with a late burst of trait diversification (Blomberg et al. 2003; table 3). This was also the case for PC1 for chemical signaling (fig. S9), male (fig. S10) and female dorsal marking (fig. S11), and vegetation niche 
Table 2: Niche comparisons among lineages at different nodes across the species tree (fig. 3)

\begin{tabular}{|c|c|c|c|c|c|}
\hline Taxonomic group, niche divergence pattern & $\begin{array}{c}\text { PC1 } \\
(25.31 \%)\end{array}$ & $\begin{array}{c}\mathrm{PC} 2 \\
(48.12 \%)\end{array}$ & $\begin{array}{c}\text { PC3 } \\
(56.89 \%)\end{array}$ & $\begin{array}{c}\text { PC4 } \\
(64.34 \%)\end{array}$ & $\begin{array}{c}\text { PC5 } \\
(70.74 \%)\end{array}$ \\
\hline \multicolumn{6}{|l|}{ Within group $1^{\text {a: }}$ : } \\
\hline $\mathrm{C}$ & 0 & 3 & 2 & 1 & 1 \\
\hline $\mathrm{D}$ & 3 & 0 & 0 & 2 & 1 \\
\hline $\mathrm{N}$ & 0 & 0 & 1 & 0 & 1 \\
\hline \multicolumn{6}{|c|}{$\begin{array}{l}\text { Ctenophorus maculatus dualis vs. Ctenophorus femoralis }+ \\
\text { groups } 1 \text { and } 2^{\mathrm{b}} \text { : }\end{array}$} \\
\hline $\mathrm{C}$ & 6 & 1 & 0 & 2 & 3 \\
\hline $\mathrm{D}$ & 1 & 5 & 6 & 3 & 2 \\
\hline $\mathrm{N}$ & 0 & 1 & 1 & 2 & 2 \\
\hline \multicolumn{6}{|l|}{ Group 3 vs. C. femoralis + group $2^{c}$ : } \\
\hline $\mathrm{C}$ & 6 & 5 & 5 & 6 & 2 \\
\hline $\mathrm{D}$ & 4 & 5 & 5 & 3 & 6 \\
\hline $\mathrm{N}$ & 0 & 0 & 0 & 1 & 2 \\
\hline \multicolumn{6}{|l|}{ C. femoralis vs. group $2^{\mathrm{d}}$ : } \\
\hline $\mathrm{C}$ & 2 & 3 & 0 & 4 & 0 \\
\hline $\mathrm{D}$ & 2 & 1 & 2 & 0 & 4 \\
\hline $\mathrm{N}$ & 0 & 0 & 2 & 0 & 0 \\
\hline \multicolumn{6}{|l|}{ Within group $2^{\mathrm{e}}$ : } \\
\hline $\mathrm{C}$ & 6 & 0 & 2 & 0 & 5 \\
\hline $\mathrm{D}$ & 0 & 5 & 4 & 5 & 0 \\
\hline $\mathrm{N}$ & 0 & 1 & 0 & 1 & 1 \\
\hline \multicolumn{6}{|l|}{ All lineage comparisons ${ }^{\mathrm{f}}$ : } \\
\hline $\mathrm{C}$ & 30 & 26 & 19 & 26 & 20 \\
\hline $\mathrm{D}$ & 25 & 27 & 22 & 23 & 20 \\
\hline $\mathrm{N}$ & 0 & 2 & 14 & 5 & 15 \\
\hline \multirow[t]{4}{*}{ Top four variables for axis } & (Bio11) & Bio19 & (Aclay) & Elevation & (LAI) \\
\hline & (Bio6) & $(\mathrm{Bio} 4)$ & ACond. & (Bio3) & (TREE) \\
\hline & Bio14 & Biol2 & AWater & STLAI & NDVI \\
\hline & (Bio1) & Bio13 & Elevation & (ACond.) & Bio2 \\
\hline Biological interpretation & Temperature & Precipitation & Soil & Complex & Vegetation \\
\hline
\end{tabular}

Note: The number of lineage comparisons showing significant niche divergence (D), conservatism (C), or not meeting statistical criteria (N) are calculated for hierarchical groups for the first five principal component (PC) scores. Boldface indicates predominant patterns in lineage comparisons ( $>75 \%$ comparisons). The top variables contributing to each PC factor are shown, with negatively loaded variables in parentheses.

${ }^{\text {a }} n=3, P<.017$.

${ }^{\text {b }} n=7, P<.007$.

${ }^{\mathrm{c}} n=10, P<.005$.

d $n=4, P<.0125$.

e $n=6, P<.0083$.

${ }^{\mathrm{f}} n=55, P<.0009$.

traits (fig. S12). Increasing rates of trait diversification are consistent with increasing average subclade disparity relative to the null, as observed in figure 3 , and while a single-peak OU model may also explain this pattern (Harmon et al. 2003), we do not observe an OU model as the model of best fit for the aforementioned traits. An AC/DC model (PD) could not be excluded for most remaining traits, but we were unable to distinguish between an AC/DC (PD) model and an OU model for PC1 for male ecomorphological traits (fig. S13) and for PC2 for chemical signaling (fig. S9), soil niche (fig. S14), and vegetation niche traits (fig. S12). PC1 for soil niche traits (fig. S14) fit either a WN or BM model, but these were generally indistinguishable for all traits using a likelihood ratio test (figs. S7-S15), and in this case, the WN model received much lower support using model log likelihood (table 3). The BM/WN and AC/DC (PD) models were indistinguishable for visual social signaling traits (PC1 and PC2; fig. S15), dorsal marking PC2 (male: fig. S10; female: fig. S11), and male ecomorphological traits PC2 (fig. S13). Indistinguishable models may be due to small sample sizes (Blomberg et al. 2003), which is likely here given that loglikelihood scores for the AC/DC (PD) model were generally 


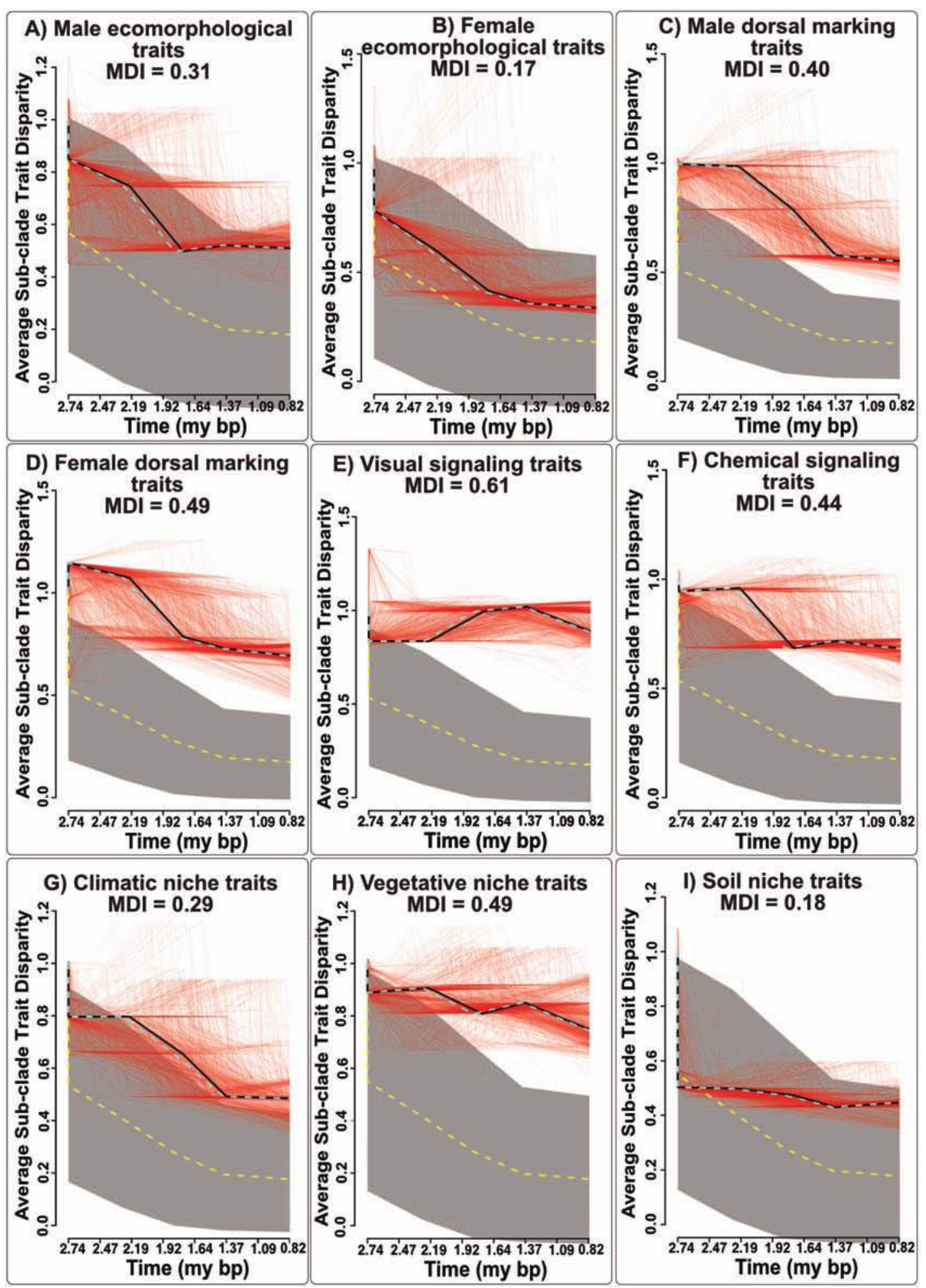

Figure 3: Disparity-through-time (DTT) plots for phenotypic and ecological traits across the Ctenophorus maculatus species complex. The median observed relative subclade trait disparity is shown (black line; fig. 2), in addition to phylogenetic uncertainty from 1,000 posterior trees (red lines; aqua dotted line indicates median). The median (yellow dotted line) and $95 \%$ confidence interval from 1,000 simulations of the null Brownian motion model from each of 1,000 posterior trees (gray shading) is also shown. Time is in millions of years before present. 
Table 3: Model parameters and log likelihood $(L)$ scores for trait evolution models compared for fit to trait data

\begin{tabular}{|c|c|c|c|c|}
\hline \multirow[b]{2}{*}{ Trait type, set, model } & \multicolumn{2}{|r|}{ PC1 } & \multicolumn{2}{|r|}{ PC1 } \\
\hline & $\log L$ & MLE parameters & $\log L$ & MLE parameters \\
\hline \multicolumn{5}{|l|}{ Male traits: } \\
\hline \multicolumn{5}{|l|}{ Ecomorphological: } \\
\hline $\mathrm{BM}$ & -23.36 & $X_{0}=-.06, \delta^{2}=5.28$ & -7.21 & $X_{0}=.06, \delta^{2}=.06$ \\
\hline $\mathrm{OU}$ & -19.68 & $\delta^{2}=197.33, \alpha=48.93$ & -8 & $\delta^{2}=210.95, \alpha=1,745.26$ \\
\hline $\mathrm{PD}$ & -19.62 & $\delta^{2}=.83, \Delta=11.27$ & -7.05 & $\delta^{2}=.04, \Delta=2.49$ \\
\hline WN & -22.6 & $X_{0}=.39, \delta^{2}=3.52$ & -10.44 & $X_{0}=.06, \delta^{2}=.28$ \\
\hline \multicolumn{5}{|l|}{ Dorsal marking: } \\
\hline $\mathrm{BM}$ & -12.24 & $X_{0}=.06, \delta^{2}=.51$ & -8.33 & $X_{0}=-.16, \delta^{2}=.24$ \\
\hline $\mathrm{OU}$ & -11.03 & $\delta^{2}=44.03, \alpha=45.29$ & -9.86 & $\delta^{2}=92.59, \alpha=112.25$ \\
\hline $\mathrm{PD}$ & -11.1 & $\delta^{2}=.23, \Delta=6.16$ & -7.94 & $\delta^{2}=.17, \Delta=2.32$ \\
\hline WN & -15 & $X_{0}=.01, \delta^{2}=1.10$ & -13.27 & $X_{0}=-.09, \delta^{2}=.82$ \\
\hline \multicolumn{5}{|l|}{ Chemical signaling: } \\
\hline $\mathrm{BM}$ & -16.86 & $X_{0}=-.004, \delta^{2}=1.15$ & -12.25 & $X_{0}=-.07, \delta^{2}=.39$ \\
\hline OU & -15.31 & $\delta^{2}=160.26, \alpha=89.87$ & -7.6 & $\delta^{2}=97.40, \alpha=648.10$ \\
\hline $\mathrm{PD}$ & -14.79 & $\delta^{2}=.38, \Delta=7.54$ & -7.65 & $\delta^{2}=.06, \Delta=100.82$ \\
\hline $\mathrm{WN}$ & -18.74 & $X_{0}=-.03, \delta^{2}=2.21$ & -10.76 & $X_{0}=.01, \delta^{2}=.41$ \\
\hline \multicolumn{5}{|l|}{ Visual signaling: } \\
\hline $\mathrm{BM}$ & -.77 & $X_{0}=-.06, \delta^{2}=.04$ & -7.12 & $X_{0}=.11, \delta^{2}=.19$ \\
\hline OU & -1.75 & $\delta^{2}=21.71, \alpha=123.14$ & -8.2 & $\delta^{2}=83.22, \alpha=128.25$ \\
\hline $\mathrm{PD}$ & -.54 & $\delta^{2}=.03, \Delta=2.25$ & -6.41 & $\delta^{2}=.12, \Delta=2.32$ \\
\hline WN & -5.68 & $X_{0}=-.02, \delta^{2}=.18$ & -12.86 & $X_{0}=-.06, \delta^{2}=.76$ \\
\hline \multicolumn{5}{|l|}{ Female traits: } \\
\hline \multicolumn{5}{|l|}{ Ecomorphological: } \\
\hline $\mathrm{BM}$ & -27.26 & $X_{0}=-.82, \delta^{2}=7.84$ & -12.32 & $X_{0}=-.10, \delta^{2}=.31$ \\
\hline OU & -26.8 & $\delta^{2}=875.15, \alpha=57.09$ & -12.76 & $\delta^{2}=211.32, \alpha=228.79$ \\
\hline $\mathrm{PD}$ & -25.98 & $\delta^{2}=3.28, \Delta=6.44$ & -11.79 & $\delta^{2}=.21, \Delta=2.16$ \\
\hline WN & -30.01 & $X_{0}=-1.45, \delta^{2}=16.92$ & -15.9 & $X_{0}=-.37, \delta^{2}=1.08$ \\
\hline \multicolumn{5}{|l|}{ Dorsal marking: } \\
\hline $\mathrm{BM}$ & -11.89 & $X_{0}=-.003, \delta^{2}=.50$ & -8.88 & $X_{0}=-.02, \delta^{2}=.28$ \\
\hline OU & -11.97 & $\delta^{2}=174.18, \alpha=154.43$ & -9.47 & $\delta^{2}=146.43, \alpha=171.11$ \\
\hline $\mathrm{PD}$ & -10.77 & $\delta^{2}=.23, \Delta=5.46$ & -8.01 & $\delta^{2}=.16, \Delta=2.53$ \\
\hline $\mathrm{WN}$ & -14.89 & $X_{0}=-.002, \delta^{2}=1.10$ & -13.52 & $X_{0}=.07, \delta^{2}=.87$ \\
\hline \multicolumn{5}{|l|}{ Ecological traits: } \\
\hline \multicolumn{5}{|l|}{ Climatic niche: } \\
\hline $\mathrm{BM}$ & -23.1 & $X_{0}=.07, \delta^{2}=3.75$ & -22.75 & $X_{0}=.25, \delta^{2}=3.47$ \\
\hline OU & -22.82 & $\delta^{2}=536.95, \alpha=65.54$ & -20.72 & $\delta^{2}=354.722, \alpha=62.17$ \\
\hline $\mathrm{PD}$ & -22.05 & $\delta^{2}=1.79, \Delta=4.00$ & -20.37 & $\delta^{2}=1.07, \Delta=7.87$ \\
\hline $\mathrm{WN}$ & -26.41 & $X_{0}=.01, \delta^{2}=9.18$ & -24.26 & $X_{0}=.06, \delta^{2}=6.12$ \\
\hline \multicolumn{5}{|l|}{ Vegetative niche: } \\
\hline $\mathrm{BM}$ & -10.35 & $X_{0}=-.04, \delta^{2}=.29$ & 4.68 & $X_{0}=.03, \delta^{2}=.01$ \\
\hline OU & -10.26 & $\delta^{2}=77.90, \alpha=116.79$ & 9.65 & $\delta^{2}=2.05, \alpha=746.15$ \\
\hline $\mathrm{PD}$ & -10.05 & $\delta^{2}=.14, \Delta=13.31$ & 9.72 & $\delta^{2}=.002, \Delta=91.17$ \\
\hline $\mathrm{WN}$ & -13.53 & $X_{0}=-.22, \delta^{2}=.79$ & 7.54 & $X_{0}=.28, \delta^{2}=.01$ \\
\hline \multicolumn{5}{|l|}{ Soil niche: } \\
\hline $\mathrm{BM}$ & -8.95 & $X_{0}=.22, \delta^{2}=.19$ & -6.64 & $X_{0}=-.07, \delta^{2}=.14$ \\
\hline OU & -10.5 & $\delta^{2}=167.62, \alpha=340.35$ & -6.48 & $\delta^{2}=63.67, \alpha=226.69$ \\
\hline $\mathrm{PD}$ & -9.07 & $\delta^{2}=.16, \Delta=2.20$ & -6.6 & $\delta^{2}=.07, \Delta=31.94$ \\
\hline $\mathrm{WN}$ & -15.55 & $X_{0}=-.05, \delta^{2}=1.15$ & -9.6 & $X_{0}=.02, \delta^{2}=.37$ \\
\hline
\end{tabular}

Note: Boldface indicates models supported by likelihood ratio tests. Italics indicate models that could not be distinguished using the lowest log $(L)$. PC $=$ principal component, $\mathrm{MLE}=$ maximum likelihood estimate, $\mathrm{BM}=$ Brownian motion, $\mathrm{OU}=$ Ornstein-Uhlenbeck, $\mathrm{PD}=$ Pagel's delta, $\mathrm{WN}=$ white noise. 
more optimal compared to other models when likelihood ratio tests suggested indistinguishable models (table 3 ).

\section{The Relationship between Phenotypic and Ecological Evolution}

There were many traits for which phylogenetic corrected tests were warranted, as indicated by significant phylogenetic signal in residuals (table S10), but there were also many that did not require correction. Tests for correlated evolution among phenotypic traits (table S11) revealed correlated evolution of chemical social signaling (CS) traits and dorsal markings, and visual social signaling traits. Analyses indicated significant evolutionary correlations between ecological niche traits and all phenotypic traits (table 4). Evolution in ecomorphological traits was significantly correlated with vegetation and climate in males but not females. In contrast, evolution in dorsal markings was significantly correlated with all ecological traits in females but only for climate and soil in males. The evolution of chemical social signaling traits was significantly correlated with all ecological traits, while only vegetation was significantly correlated with visual social signaling traits (table 4).

\section{The Relative Influence of Ecology and Spatial Overlap on Trait Variation}

The most important variable explaining dorsal marking variation was phylogeny $(18 \% ; F=3.4 ; P<.01)$, with comparatively smaller effects explained by spatial overlap (3\%; $F=1.4 ; P>.05)$ and environmental factors $(9 \% ; F=2.2$; $P<.05$; table $S 12)$. For chemical signaling traits, environmental factors were the most important in predicting variation $(49 \% ; F=6.1 ; P<.001)$, where spatial overlap (4\%; $F=1.8 ; P>.05$ ) and phylogeny (fig. $4 A ; 2 \% ; F=1.3$; $P>.05)$ appeared less important. Spatial overlap (33\%; $F=4.4 ; P<.01)$ predicted the greatest proportion of variance in visual social signaling traits relative to moderate amounts of variation explained by environmental factors $(15 \% ; F=3.7 ; P<.05)$ and phylogeny (fig. $4 B ; 13 \%$; $F=3.4 ; P>.05)$. Variation in all traits predicted by combinations of variables was relatively small. Spatial overlap and environment accounted for a small proportion of variation in dorsal marking $(1 \% ; F=2.0 ; P<.05)$ and chemical $(8 \%$; $F=5.7 ; P<.001)$ and visual $(0.4 \% ; F=4.7 ; P<.001)$ social signaling traits. Other fractions of explainable variation in chemical signaling traits included a combination of spatial overlap and phylogeny $(3 \% ; F=2.0 ; P>.05)$. For visual signaling (VS) traits and dorsal markings (DM), a combination of environment and phylogeny (VS: $1 \%$; $F=5.7$; $P<.001$; DM: $12 \% ; F=3.9 ; P<.01)$ explained a significant fraction of variation. For visual signaling traits alone, a combination of environment, phylogeny, and spatial overlap to- gether $(3 \% ; F=4.8 ; P<.001)$ explained a significant fraction of variation. Negative variation proportions for shared variation (fig. 4) among partitions are due to suppressor variables (i.e., the explanatory variable has low/no correlation with the response variable but covaries with other explanatory variables related to the response variable) or to strong correlations among explanatory variables of opposite signs (Peres-Neto et al. 2006). Unexplained variance was moderate for both the chemical social signaling (39\%) and visual social signaling (39\%) traits but high for dorsal marking (60\%) traits (fig. 4). Environmental variation in climate only contributed to variance in spatial overlap ( $F=1.5 ; P<.05)$, suggesting that, for the most part, spatial overlap does not necessarily correlate with ecological overlap between lineages.

\section{Discussion \\ Phylogenetic Divergence and the Development of Australian Arid Habitats}

The creation of new ecological niches often drives rapid adaptive speciation (Rundle et al. 2000; Grant and Grant 2008), resulting in phylogenetic divergence associated with the timing of niche creation (Rabosky 2009; Glor 2010). Several important events linked to the creation and diversification of arid sand habitats, in which the Ctenophorus maculatus species complex exclusively occurs (Wilson and Swan 2008), correspond to patterns of lineage divergence (fig. 2). This result suggests that the creation of new ecological niches was involved in the speciation of $C$. maculatus lineages. Aridification of Australia began in the late Miocene (Bowler 1976), with the appearance of arid habitats amid intensifying aridity driven by northern hemisphere glaciation $\sim 3$ million years ago (Hesse 2010). During this time, deep sand deposits formed in southwestern Australia (Clarke 1994). The ancestor of the C. maculatus complex originated within this period (fig. 2), and all basal lineages are currently distributed within southwestern Australia (figs. 1, 2). Extensive dune system formation throughout Australia is linked to the establishment of Milankovitch cycling ( $\sim$ million years ago; Fujioka et al. 2009; Hesse 2010), with dune systems developing $\sim 500,000$ years ago and dramatically expanding $\sim 350,000$ years ago (Fujioka and Chappell 2010). Diversification of arid sand habitats tightly corresponds with a cluster of speciation events within the $C$. maculatus species complex (fig. 2) and thus may be linked to the recent diversification in the group.

\section{Patterns of Ecological and Phenotypic Evolution}

Ecological opportunity (i.e., exposure to new habitats) and associated increases in phenotypic diversity are key components involved in the rapid diversification process that leads 
Table 4: Results of tests for correlated evolution between ecological and phenotypic data sets for the two main axes of variation

\begin{tabular}{|c|c|c|c|c|c|c|}
\hline \multirow[b]{2}{*}{ Sex, data set, axis } & \multicolumn{2}{|c|}{ Climate } & \multicolumn{2}{|c|}{ Vegetation } & \multicolumn{2}{|c|}{ Soil } \\
\hline & 1 & 2 & 1 & 2 & 1 & 2 \\
\hline \multicolumn{7}{|l|}{ Female: } \\
\hline \multicolumn{7}{|c|}{ Ecomorphological traits: } \\
\hline 1 & $-.10^{\mathrm{B}}$ & $.02^{\mathrm{B}}$ & $-.07^{\mathrm{B}}$ & $-.05^{\mathrm{B}}$ & $.24^{\mathrm{B}}$ & $-.10^{\mathrm{B}}$ \\
\hline 2 & $.04^{\mathrm{B}}$ & $-.06^{\mathrm{A}}$ & $.09^{\mathrm{A}}$ & $-.07^{\mathrm{A}}$ & $-.03^{\mathrm{B}}$ & $-.06^{\mathrm{B}}$ \\
\hline \multicolumn{7}{|c|}{ Dorsal marking traits: } \\
\hline 1 & $.51^{* *, \mathrm{~B}}$ & $.10^{\mathrm{B}}$ & $.34^{*, \mathrm{~B}}$ & $.14^{\mathrm{B}}$ & $-.08^{\mathrm{B}}$ & $.26^{\mathrm{B}}$ \\
\hline 2 & $.03^{\mathrm{A}}$ & $.30^{*, \mathrm{~B}}$ & $-.10^{\mathrm{A}}$ & $.45^{*, \mathrm{~A}}$ & $.60^{* *, B}$ & $.003^{\mathrm{A}}$ \\
\hline \multicolumn{7}{|l|}{ Male: } \\
\hline \multicolumn{7}{|c|}{ Ecomorphological traits: } \\
\hline 1 & $-.10^{\mathrm{B}}$ & $-.03^{\mathrm{B}}$ & $-.05^{\mathrm{B}}$ & $-.10^{\mathrm{B}}$ & $.02^{\mathrm{B}}$ & $-.09^{\mathrm{B}}$ \\
\hline 2 & $.35^{*, \mathrm{~B}}$ & $-.10^{\mathrm{A}}$ & $.45^{*}, \mathrm{~A}$ & $.00^{\mathrm{B}}$ & $.02^{\mathrm{A}}$ & $.28^{\mathrm{A}}$ \\
\hline \multicolumn{7}{|c|}{ Dorsal markings traits: } \\
\hline 1 & $.85^{* * *, \mathrm{~B}}$ & $.17^{\mathrm{B}}$ & $.15^{\mathrm{B}}$ & $-.05^{\mathrm{B}}$ & $.03^{\mathrm{B}}$ & $.11^{\mathrm{B}}$ \\
\hline 2 & $-.04^{\mathrm{A}}$ & $.23^{\mathrm{B}}$ & $-.03^{\mathrm{A}}$ & $.11^{\mathrm{A}}$ & $.07^{\mathrm{B}}$ & $.36^{*}, \mathrm{~A}$ \\
\hline \multicolumn{7}{|c|}{ Visual signaling traits: } \\
\hline 1 & $.11^{\mathrm{A}}$ & $-.17^{\mathrm{A}}$ & $.52^{* *, \mathrm{~A}}$ & $-.11^{\mathrm{A}}$ & $-.11^{\mathrm{A}}$ & $.19^{\mathrm{A}}$ \\
\hline 2 & $.01^{\mathrm{A}}$ & $-.10^{\mathrm{A}}$ & $.22^{\mathrm{A}}$ & $-.11^{\mathrm{A}}$ & $-.08^{\mathrm{A}}$ & $.19^{\mathrm{A}}$ \\
\hline \multicolumn{7}{|c|}{ Chemical signaling traits: } \\
\hline 1 & $.08^{\mathrm{B}}$ & $.64^{* *, \mathrm{~B}}$ & $.50^{* *, \mathrm{~B}}$ & $.08^{\mathrm{B}}$ & $.00^{\mathrm{B}}$ & $.35^{*, \mathrm{~B}}$ \\
\hline 2 & $-.04^{\mathrm{B}}$ & $-.10^{\mathrm{B}}$ & $-.09^{\mathrm{B}}$ & $.14^{\mathrm{B}}$ & $-.07^{\mathrm{B}}$ & $-.10^{\mathrm{B}}$ \\
\hline \multicolumn{7}{|c|}{$\begin{array}{l}\text { Note: Results are reported from analyses either correcting for phylogenetic signal where warranted (indicated by a superscript } \mathrm{A} \text { ), as indicated by significant } \\
\text { phylogenetic signal in regression residuals (table } \mathrm{S} 12 \text { ), or alternatively uncorrected analyses (indicated by a superscript } \mathrm{B} \text { ). For phylogenetically corrected analyses, } \\
\text { shown are average adjusted } R^{2} \text { values across } 1,000 \text { trees from the posterior distribution, with significant relationships shown in boldface. Average adjusted } R^{2} \text { values are } \\
\text { shown for uncorrected analyses. } \\
{ }^{*} P \leq .05 \text {. }\end{array}$} \\
\hline
\end{tabular}

to adaptive radiation (see review in Yoder et al. 2010). In the C. maculatus species complex, we show that there has been considerable diversification in both ecological niche traits and phenotypic traits, including those linked to fitness and social signaling. Persistent niche divergence indicates that lineages differ dramatically in ecological space, rather than simply representing allopatric ecological analogues. Phylogenetically informed comparisons (table 2; fig. 2) suggest that shifts in temperature niche may have been important in allowing lineages to colonize arid regions as the turnover between humid and arid ecosystems progressed (Bowler 1976). Tests to identify the best-fit model of trait evolution suggest that rates of many ecological and phenotypic traits have increased toward the present (table 3; figs. S7S15), albeit with limited support in some traits likely due to small sample sizes in our data set (Boettiger 2012). High subclade disparity relative to the null, in general, but particularly toward the present, further supports that lineages in different subclades have increasingly diversified in ecological niche and phenotypic trait space toward the present but also that lineages have reinvaded similar trait spaces independently (Harmon et al. 2003; fig. 3). Increasing relative subclade disparity in phenotypic and ecological traits has been seen to a more limited extent in some adaptive radiations (Boucher et al. 2012; Muschick et al. 2012), but the striking increases observed in our study are noteworthy and suggest rampant diversification and independent convergent evolution.

Increasing niche diversity, seen particularly in vegetative niche traits, was likely created by climatic events driving sand plain and dune system development in the Australian arid zone (Fujioka et al. 2009; Fujioka and Chappell 2010; Hesse 2010), which are also linked to speciation events in the C. maculatus species complex (fig. 2). Dune systems can vary dramatically in vegetation cover, resulting in variation in the extent of open sand swathes and sand movement (Hesse and Simpson 2006), but dunes tend to harbor sparser vegetation than sand plain habitats, which are characterized by shallow stable sands and thicker vegetation (Mabbutt 1968).

\section{Ecological Adaptation and Social Signal Evolution as Drivers of Diversification}

Our study represents the first of its kind to quantify ecological niche and phenotypic evolution in Australian desert 

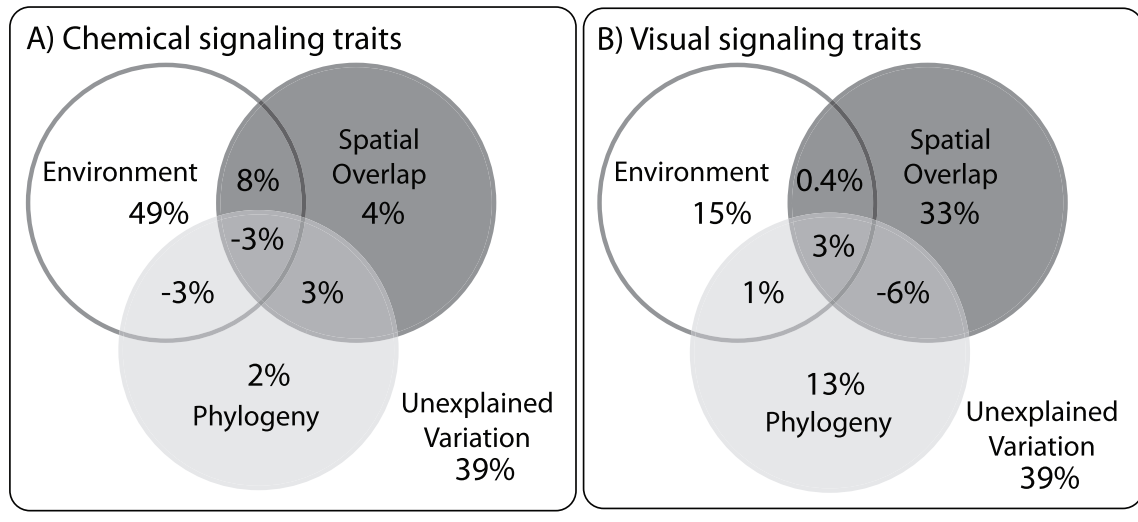

Figure 4: Proportions of variance independently explained by the environment (white), spatial overlap (dark gray), and the phylogenetic relationships among lineages (light gray) are shown for chemical $(A)$ and visual $(B)$ signaling traits. Circle overlap shows the proportion of variance explained by combinations of these factors, with unexplained variance listed outside circles.

taxa, despite the fact that for many taxa (reviewed in Byrne et al. 2008), and especially the amphibolurine agamids (Melville et al. 2001; Harmon et al. 2003), the creation of these habitats has been qualitatively inferred as a driver of diversification. Moderate to strong evolutionary correlations among ecological niche traits, vegetation niche particularly, and all phenotypic traits suggest that a recent burst of phenotypic diversification in ecomorphological, dorsal marking, and visual and chemical social signaling traits is adaptive (table 4). The lack of an evolutionary correlation between ecological factors and ecomorphology in females, which is present in males, may reflect lower sampling in females (Harmon and Losos 2005); however, ecomorphological associations with habitat have been found to be stronger in male lizards (Herrel et al. 2002). Limited evidence for correlated evolution between ecomorphological traits and ecological factors compared to other phenotypic traits could reflect slower rates of ecomorphological evolution compared with other phenotypic traits (Streelman and Danley 2003) or divergent functional roles among phenotypic traits (Cheverud et al. 1989). Both are supported by a lack of correlated evolution between ecomorphology and other phenotypic traits (both sexes). Ecomorphological evolution in lizards is often driven by natural selection on locomotory performance in different habitats (Garland and Losos 1994; Melville and Swain 2000; Herrel et al. 2002; Goodman et al. 2009). We hypothesize that the relationship with vegetation observed here reflects repeated evolution of different body forms in open dune habitats versus more heavily vegetated sand plain habitats (Mabbutt 1968; Hesse and Simpson 2006) and that ecological selection is stronger on males than it is on females.

While evolution in dorsal marking traits in amphibolurine agamids is considered constrained by natural selection and related to predator avoidance (Stuart-Fox and
Ord 2004), other studies have shown that dorsal color and pattern complexity may be under strong sexual selection (Chen et al. 2012, 2013). Correlated evolution between dorsal marking characters and climate and soil (both sexes) and vegetation (females only; table 4) suggests natural selection influences dorsal markings in the C. maculatus complex. Dorsal coloration in lizards signals early adaptive speciation driven by soil color (Rosenblum 2006; Rosenblum et al. 2007; Rosenblum and Harmon 2010) and is subject to local adaptation (Stuart-Fox et al. 2004). Ecologically driven divergence is also supported by the substantial differences in background coloration observed between C. maculatus lineages (fig. 1), which are likely driven by soil color variation across the sand plains and dunes of southern Australia (Nanson et al. 1992; Pell et al. 1999). Sexual differences in the strength of ecological selection in dorsal marking traits, shown here in the broader association between ecological and dorsal marking traits in females relative to males, have also been observed in other amphibolurines (Stuart-Fox et al. 2004), suggesting selection for crypsis is stronger in females.

Alternatively, differences between the sexes may reflect different functional roles, in that dorsal marking complexity in males may also function in social signaling (Chen et al. 2012, 2013). Correlated evolution of chemical social signaling traits with visual social signaling and dorsal marking traits supports a common male social signaling role for these traits, but it could also indicate simultaneous and multifarious ecological selection (e.g., Rosenblum and Harmon 2010; table 4). The implication that ecological factors mediate the evolution of social signaling traits in lizards (chemical: Alberts 1992; Iraeta et al. 2011; visual: Endler 1992, 1993; LeBas and Marshall 2000) is supported by the evolutionary correlation between all ecological factors and chemical signaling traits and between vegetative 
niche and visual signaling traits in the $C$. maculatus species complex (table 4). Chemical signaling traits in lizards have been noted to covary with precipitation regime, which is hypothesized to impact the stability of volatile chemical cues delivered through these structures (Iraeta et al. 2011). We see evidence of this in the C. maculatus species complex, with lineages occupying semiarid habitats showing both larger and more extensive chemical signaling traits than lineages occupying arid habitats. Adaptive evolution of visual social signaling traits with vegetation could reflect natural selection on visual signal transmission related to habitat openness (Endler 1992, 1993) or substrate reflectance (LeBas and Marshall 2000). Regardless of the specific ecological mechanism, ecological divergence mediates social signaling trait evolution in C. maculatus lineages, likely by acting on the delivery and perception of those signals in different ecological contexts.

Still, given that chemical signaling traits are linked to conspecific chemosensory cues involved in territory marking and mate choice (Cooper 1994) and that evolution in visual signaling and dorsal marking traits has been linked to sexual selection (LeBas and Marshall 2000; Stuart-Fox and Ord 2004; Chen et al. 2012, 2013), a role in social interactions for these traits cannot be excluded. Considering that lineage parapatry does not explain variation in either dorsal marking or chemical signaling traits (fig. 4), this could mean that these traits are involved in social interactions between conspecifics in specific environments or that they are purely adaptive in nature. Alternatively, our results clearly show that variation in visual social signals, rather than being explained by purely ecological selection (e.g., $\mathrm{Ng}$ et al. 2013) or the phylogenetic relationships among taxa, are better explained by the spatial overlap between lineages (fig. 4). Spatial overlap between lineages, a proxy representing the opportunity for interactions between lineages, thus potentially illustrates trait divergence in response to premating reinforcement of lineage boundaries (West-Eberhard 1983; Butlin 1987), as has been found in other lizards (i.e., Robertson and Rosenblum 2009), and supports our prediction that social interactions between lineages promote divergence in visual signaling traits but with some ecological effects. Without information on the presence of coevolving divergent female preferences and visual social signals and how this relates to the incidence of hybridization, it is difficult to explicitly infer an interaction between ecological and sexual selection here. However, reinforcement is often evidence for sexual selection for good genes (Maan and Seehausen 2011). Our results suggest that, in this case, ecologically driven divergence among speciating lineages is reinforced via visual social signaling traits, themselves under an element of divergent ecological selection, where ecologically distinct lineages have the potential to interact, thus explaining dramatic diversification in these traits.

\section{Conclusions}

While often considered in isolation, the combined effects of adaptive and social signal evolution could be incredibly important in organismal diversification. The Ctenophorus maculatus species complex represents a group whose diversification is associated with the development and diversification of arid sand habitats across southern Australia. The creation of the arid zone coincides with the beginning of a subsequent accumulation of increasingly divergent habitats, particularly vegetative habitats, which have driven the evolution of a multifarious suite of traits involved in maximizing locomotory performance, predator avoidance, and social signaling. We speculate that differences in the role of ecology and spatial overlap in chemical versus visual social signals could exemplify their differential roles in conspecific versus interspecific signals, respectively. We also suggest that boundaries among ecologically distinct lineages are reinforced by visual social signaling traits in parapatry. Contrary to previous studies, our results suggest that a combination of adaptive evolution and social signal evolution likely explain rapid diversification in amphibolurine agamids, thus highlighting the importance of empirical studies on the evolution of ecological and social signaling traits together. Furthermore, our study provides an empirical example supporting theories that sexual selection and ecological selection alone are unlikely to lead to speciation (Nosil et al. 2009; Servedio and Bürger 2014) and that the potential for species interactions may be key to allowing these two forces to work together.

\section{Acknowledgments}

We thank two reviewers (M. R. E. Symonds and one anonymous reviewer), Associate Editor S. J. Steppan, and Editor in Chief J. L. Bronstein for thoughtful and productive feedback that dramatically improved the manuscript. We also thank C. Edwards for illustrations; S. Ford, V. Ford, J. Hale, and G. Kay for field assistance; A. Dornburg, E. Forrestel, M. N. Hutchinson, and M. J. Sistrom for methodological discussions; and S. Donnellan, P. Doughty, and R. Sadlier for specimens and tissues. Funding was provided by the Australian National Wildlife Collection (D.L.E.) and the Australian Research Council (J.S.K. and J.E.M.).

\section{Literature Cited}

Alberts, A. C. 1992. Constraints on the design of chemical communication systems in terrestrial vertebrates. American Naturalist 139(suppl.):S62-S89.

Arnegard, M. E., P. B. McIntyre, L. J. Harmon, M. L. Zelditch, W. G. R. Crampton, J. K. Davis, J. P. Sullivan, S. Lavoué, and C. D. Hopkins. 
2010. Sexual signal evolution outpaces ecological divergence during electric fish species radiation. American Naturalist 176:335-356.

Blomberg, S. P., T. Garland Jr., and A. R. Ives. 2003 Testing for phylogenetic signal in comparative data: behavioral traits are more labile. Evolution 57:717-745.

Boettiger, C., G. Coop, and P. Ralph. 2012. Is your phylogeny informative? measuring the power of comparative methods. Evolution 66:2240-2251.

Borcard, D., P. Legendre, and P. Drapeau. 1992. Partialling out the spatial component of ecological variation. Ecology 73:1045-1055.

Boucher, F. C., W. Thuiller, C. Roquet, R. Douzet, S. Aubert, N. Alvarez, and S. Lavergne. 2012. Reconstructing the origins of high-alpine niches and cushion life form in the genus Androsace s.l. (Primulaceae). Evolution 66:1255-1268.

Boughman, J. W. 2001. Divergent sexual selection enhances reproductive isolation in sticklebacks. Nature 411:944-948.

- 2002. How sensory drive can promote speciation. Trends in Ecology and Evolution 17:571-577.

Bowler, J. M. 1976. Aridity in Australia: age, origins and expression in Aeolian landforms and sediments. Earth Science Reviews 12:279310.

Butler, M. A., and A. A. King. 2004. Phylogenetic comparative analysis: a modeling approach for adaptive evolution. American Naturalist 164:683-695.

Butlin, R. 1987. Speciation by reinforcement. Trends in Ecology and Evolution 2:8-13.

Byrne, M., D. K. Yeates, L. Joseph, M. Kearney, J. Bowler, M. A. J. Williams, S. Cooper, et al. 2008. Birth of a biome: insights into the assembly and maintenance of the Australian arid zone biota. Molecular Ecology 17:4398-4417.

Carlson, B. A., A. M. Hasan, M. Hollmann, D. B. Miller, L. J. Harmon, and M. A. Arnegard. 2011. Brain evolution triggers increased diversification of electric fishes. Science 332:583-586.

Chen, I.-P., D. Stuart-Fox, A. F. Hugall, and M. R. E. Symonds. 2012. Sexual selection and the evolution of complex color pattern in dragon lizards. Evolution 66:3605-3614.

Chen, I.-P., M. R. E. Symonds, J. Melville, and D. Stuart-Fox. 2013. Factors shaping the evolution of colour patterns in Australian agamid lizards (Agamidae): a comparative study. Biological Journal of the Linnean Society 109:101-112.

Cheverud, J. M., G. P. Wagner, and M. M. Dow. 1989. Methods for the comparative analysis of variation patterns. Svstematic Zoology 38:201-213.

Clarke, J. D. A. 1994. Geomorphology of the Kambalda region, Western Australia. Australian Journal of Earth Sciences 41:229-239.

Cooper, W. E. 1994. Chemical discrimination by tongue-flicking in lizards: a review with hypotheses on its origin and its ecological and phylogenetic relationships. Journal of Chemical Ecology 20: 439-487.

Covacevich, J., P. Couper, R. E. Molnar, G. Witten, and W. Young. 1990. Miocene dragons from Riversleigh: new data on the history of the family Agamidae (Reptilia: Squamata) in Australia. Memoirs of the Queensland Museum 29:339-360.

Drummond, A. J., and A. Rambaut. 2007. BEAST: Bayesian evolutionary analysis by sampling trees. BMC Evolutionary Biology 7:214.

Dray, S. 2013. spacemakeR: spatial modelling. R package. Version 0.0-5/r113. http://R-Forge.R-project.org/projects/sedar/.

Dray, S., and A. B. Dufour. 2007. The ade4 package: implementing the duality diagram for ecologists. Journal of Statistical Software 22:1-20.
Edwards, D. L., J. S. Keogh, and L. L. Knowles. 2012. Effects of vicariant barriers, habitat stability, population isolation and environmental features on species divergence in the south-western Australian coastal reptile community. Molecular Ecology 21:3809-3822.

Edwards, D. L., J. S. Keogh, and J. D. Roberts. 2007. Impact of PlioPleistocene arid cycling on the population history of a southwestern Australian frog. Molecular Ecology 16:2782-2796.

Edwards, D. L., and L. L. Knowles. 2014. Species detection and individual assignment in species delimitation: can integrative data increase efficacy? Proceedings of the Roval Society B: Biological Sciences 281:20132765.

Edwards, D. L., and J. Melville. 2011. Extensive phylogeographic analysis and morphological diversity in Diporiphora nobbi (Agamidae) leads to a taxonomic review and a new species description. $\underline{\text { Journal of }}$ Herpetology 45:530-546.

Edwards, D. L., J. Melville, L. Joseph, and J. S. Keogh. 2015. Data from: Ecological divergence, adaptive diversification, and the evolution of social signaling traits: an empirical study in arid Australian lizards. Dryad Digital Repository, American Naturalist, http:// dx.doi.org/10.5061/dryad.7nm09.

Endler, J. A. 1992. Signals, signal conditions, and the direction of evolution. American Naturalist 139(suppl.):S125-S153.

- 1993. Some general comments on the evolution and design of animal communication systems. Philosophical Transactions of the Roval Society B: Biological Sciences 340:215-225.

Endler, J. A., and A. L. Basolo. 1998. Sensory ecology, receiver biases and sexual selection. Trends in Ecology and Evolution 13:415-420.

Evans, M. E. K., S. A. Smith, R. S. Flynn, and M. J. Donoghue. 2009. Climate, niche evolution, and diversification of the "bird-cage" evening primroses (Oenothera, sections Anogra and Kleinia). American Naturalist 173:225-240.

Felsenstein, J. 1985. Phylogenies and the comparative method. American Naturalist 125:1-15.

-2008. Comparative methods with sampling error and withinspecies variation: contrasts revisited and revised. American Naturalist 171:713-725.

Fujioka, T., and J. Chappell. 2010. History of Australian aridity: chronology in the evolution of arid landscapes. Geological Society of London Special Publication 346:121-139.

Fujioka, T., J. Chappell, L. K. Fifield, and E. J. Rhodes. 2009. Australian desert dune fields initiated with Pliocene-Pleistocene global climatic shift. Geology 37:51-54.

Garland Jr., T. 1992. Rate tests for phenotypic evolution using phylogenetically independent contrasts. American Naturalist 140:509-519.

Garland Jr., T., P. H. Harvey, and A. R. Ives. 1992. Procedures for the analysis of comparative data using phylogenetically independent contrasts. Systematic Biology 41:18-32.

Garland Jr., T., and J. B. Losos. 1994. Ecological morphology of locomotor performance in squamate reptiles. Pages 240-302 in P. C. Wainwright and S. M. Reilly, eds. Ecological morphology: integrative organismal biology. University of Chicago Press, Chicago.

Gavrilets, S., ed. 2004. Fitness landscapes and the origin of species. Princeton University Press, Princeton, NJ.

Gavrilets, S., and J. B. Losos. 2009. Adaptive radiation: contrasting theory with data. Science 323:732-737.

Glor, R. E. 2010. Phylogenetic insights on adaptive radiation. Annual Reviews in Ecology and Evolution 41:251-270.

Goodman, B. A., D. B. Miles, and L. Schwarzkopf. 2009. Life on the rocks: habitat use drives morphological and performance evolution in lizards. Ecology 89:3462-3471. 
Grant, P. R., and B. R. Grant, eds. 2008. How and why species multiply: the radiation of Darwin's finches. Princeton University Press, Princeton, NJ.

Harmon, L. J., and J. B. Losos. 2005. The effect of intraspecific sample size on type I and type II error rates in comparative studies. Evolution 59:2705-2710.

Harmon, L. J., J. B. Losos, J. Davies, R. G. Gillespie, J. L. Gittleman, W. B. Jennings, K. H. Kozak, et al. 2010. Early bursts of body size and shape evolution are rare in comparative data. Evolution 64:2385-2396.

Harmon, L. J., J. A. Schulte, A. Larson, and J. B. Losos. 2003. Tempo and mode of evolutionary radiation in iguanian lizards. Science 301:961-964.

Harmon, L. J., J. T. Weir, C. D. Brock, R. E. Glor, and W. Challenger. 2008. GEIGER: investigating evolutionary radiations. Bioinformatics 24:129-131.

Heled, J., and A. J. Drummond. 2010. Bayesian inference of species trees from multilocus data. Molecular Biology and Evolution 27: 570-580.

Henle, K. 1991. Life history patterns in lizards of the arid and semiarid zone of Australia. Oecologia (Berlin) 88:347-358.

Herrel, A., J. J. Meyers, and B. Vanhooydonck. 2002. Relations between microhabitat use and limb shape in phrynosomatid lizards. Biological Journal of the Linnean Society 77:149-163.

Hesse, P. P. 2010. The Australian desert dunefields: formation and evolution in an old, flat, dry continent. Geological Society of London Special Publication 346:141-164.

Hesse, P. P., and R. L. Simpson. 2006. Variable vegetation cover and episodic sand movement on longitudinal desert sand dunes. Geomorphology 81:276-291.

Hijmans, R. J., S. E. Cameron, J. L. Parra, P. G. Jones, and A. Jarvis. 2005. Very high resolution interpolated surfaces for global land areas. International Journal of Climatology 25:1965-1978.

Hoskin, C. J., and M. Higgie. 2010. Speciation via species interactions: the divergence of mating traits within species. Ecology Letters 13: 409-420.

Hugall, A. F., R. Foster, M. Hutchinson, and M. S. Y. Lee. 2008. Phylogeny of Australasian agamid lizards based on nuclear and mitochondrial genes: implications for morphological evolution and biogeography. Biological Journal of the Linnean Society 93:343-358.

Hunt, G. 2007. The relative importance of directional change, random walks, and stasis in the evolution of fossil lineages. Proceedings of the National Academy of Sciences of the USA 104:404-408.

Husson, F., J. Josse, S. Lê, and J. Mazet. 2013. FactoMineR: multivariate exploratory data analysis and data mining with R. R package. Version 1.25. http://CRAN.R-project.org/package $=$ FactoMineR .

Iraeta, P., C. Monasterio, A. Salvador, and J. A. Díaz. 2011. Sexual dimorphism and interpopulation differences in lizard hind limb length: locomotor performance or chemical signaling. Biological Lournal of the Linnean Society 104:318-329.

LeBas, N. R., and N. J. Marshall. 2000. The role of colour in signaling and male choice in the agamid lizard Ctenophorus ornatus. Proceedings of the Roval Society B: Biological Sciences 267:445-452.

Liu, C., P. M. Berry, T. P. Dawson, and R. G. Pearson. 2005. Selecting thresholds of occurrence in the prediction of species distributions. Ecography 28:385-393.

Lleonart, J., J. Salat, and G. J. Torres. 2000. Removing allometric effects of body size in morphological analysis. Lournal of Theoretical Biology 205:85-93.

Losos, J. B. 1990. Ecomorphology, performance capability, and scaling of West Indian anolis lizards: an evolutionary analysis. Ecological Monographs 60:369-388.
Maan, M. E., and O. Seehausen. 2011. Ecology, sexual selection and speciation. Ecology Letters 14:591-602.

Mabbutt, J. A. 1968. Aeolian landforms in central Australia. Australian Geographical Studies 6:139-150.

Maia, R., D. R. Rubenstein, and M. D. Shawkey. 2013. Key ornamental innovations facilitate diversification in an avian radiation. Proceedings of the National Academv of Sciences of the USA 110:1068710692.

Masta, S., and W. Maddison. 2002. Sexual selection driving diversification in jumping spiders. Proceedings of the National Academv of Sciences of the USA 99:4442-4447.

McCormack, J. E., J. Heled, K. S. Delaney, A. T. Peterson, and L. L. Knowles. 2011. Calibrating divergence times on species trees versus gene trees: implications for speciation history of Aphelocoma jays. Evolution 65:184-202.

McCormack, J. E., A. J. Zellmer, and L. L. Knowles. 2010. Does niche divergence accompany allopatric divergence in Aphelocoma jays as predicted under ecological speciation? insights from tests with niche models. Evolution 64:1231-1244.

McLean, C. A., D. Stuart-Fox, and A. Mousalli. 2014. Phylogeographic structure, demographic history and morph composition in a colour polymorphic lizard. Iournal of Evolutionary Biology 27:2123-2137.

Melville, J., J. Schulte, and A. Larson. 2001. A molecular phylogenetic study of ecological diversification in the Australian lizard genus Ctenophorus. Journal of Experimental Zoology 291:339-353.

Melville, J., and R. Swain. 2000. Evolutionary relationships between morphology, performance and habitat openness in the lizard genus Niveoscincus (Scincidae: Lygosominae). Biological Journal of the Linnean Society 70:667-683.

Mendelson, T. C., and K. L. Shaw. 2005. Sexual behaviour: rapid speciation in an arthropod. Nature 433:375-376.

Muschick, M., A. Indermaur, W. Salzburger. 2012. Convergent evolution within an adaptive radiation of cichlid fishes. Current Biology 24:2362-2368.

Nanson, G. C., X. Y. Chen, and D. M. Price. 1992. Lateral migration, thermoluminescence chronology and colour variation of longitudinal dunes near Birdsville in the Simpson Desert, central Australia. Earth Surface Processes and Landforms 17:807-819.

Ng, J., E. L. Landeen, R. M. Logsdon, and R. E. Glor. 2013. Correlation between Anolis lizard dewlap phenotype and environmental variation indicates adaptive divergence of a signal important in sexual selection and species recognition. Evolution 67:573582.

Nosil, P., L. J. Harmon, and O. Seehausen. 2009. Ecological explanations for (incomplete) speciation. Trends in Ecology and Evolution 24:145-156.

Oksanen, J., F. G. Blanchet, R. Kindt, P. Legendre, P. R. Minchin, R. B. O'Hara, G. L. Simpson, P. Solymos, M. H. H. Stevens, and H. Wagner. 2013. vegan: community ecology package. R package. Version 2.0-7. http://CRAN.R-project.org/package $=$ vegan.

Olsson, M. 2001. No female choice in Mallee dragon lizards, Ctenophorus fordi. Evolutionarv Ecology 15:129-141.

Ord, T. J., and D. Stuart-Fox. 2006. Ornament evolution in dragon lizards: multiple gains and widespread losses reveal a complex history of evolutionary change. Journal of Evolutionary Biology 19:797-808.

Pagel, M. 1999. Inferring the historical pattern of biological evolution. Nature 401:877-884.

Paradis, E., J. Claude, and K. Strimmer. 2004. APE: analyses of phylogenetics and evolution in R language. Bioinfomatics 20:289-290. 
Pell, S. D., A. R. Chivas, and I. S. Williams. 1999. Great Victoria Desert: development and sand provenance. Australian Journal of Earth Sciences 46:289-299.

Pennell, M. W., and L. J. Harmon. 2013. An integrative view of phylogenetic comparative methods: connections to population genetics, community ecology, and paleobiology. Annals of the New York Academv of Sciences 1289:90-105.

Peres-Neto, P. R., P. Legendre, S. Dray, and D. Borcard. 2006. Variation partitioning of species data matrices: estimation and comparison of fractions. Ecology 87:2614-2625.

Rabosky, D. L. 2009. Ecological limits and diversification rate: alternative paradigms to explain the variation in species richness among clades and regions. Ecology Letters 12:735-743.

Rambaut, A., and A. J. Drummond. 2007. Tracer v1.4. http://beast .bio.ed.ac.uk/Tracer

Revell, L. J. 2010. Phylogenetic signal and linear regression on species data. Methods in Ecology and Evolution 1:319-329.

- 2012. phytools: an R package for phylogenetic comparative biology (and other things). Methods in Ecology and Evolution 3:217-223.

Robertson, J. M., and E. B. Rosenblum. 2009. Rapid divergence of social signal coloration across the White Sands ecotone for three lizard species under strong natural selection. Biological Journal of the Linnean Society 98:243-255.

Rosenblum, E. B. 2006. Convergent evolution and divergent selection: lizards at the White Sands ecotone. American Naturalist 167: 1-15.

Rosenblum, E. B., and L. J. Harmon. 2010. "Same same but different": replicated ecological speciation at White Sands. Evolution 65:946-960.

Rosenblum, E. B., M. J. Hickerson, and C. Moritz. 2007. A multilocus perspective on colonization accompanied by selection and gene flow. Evolution 61:2971-2985.

Rundle, H. D., L. Nagel, J. W. Boughman, and D. Schluter. 2000. Natural selection and parallel speciation in sympatric sticklebacks. Science 287:306-308.

Safran, R. J., E. S. C. Scordato, L. B. Symes, R. L. Rodriguez, and T. C. Mendelson. 2013. Contributions of natural and sexual selection to the evolution of premating reproductive isolation: a research agenda. Trends in Ecology and Evolution 28:643-650.

Scheet, P., and M. Stephens. 2006. A fast and flexible statistical model for large-scale population genotype data: applications to inferring missing genotypes and haplotypic phase. American Journal of $\mathrm{Hu}$ man Genetics 78:629-644.

Schluter, D., 2009. Evidence for ecological speciation and its alternative. Science 323:737-741
Scordato, E. S. C., L. B. Symes, T. C. Mendelson, and R. J. Safran 2014. The role of ecology in speciation by sexual selection: a systematic empirical review. Heredity 105:782-794.

Seehausen, O., Y. Terai, I. S. Magalhaes, K. L. Carelton, H. D. J. Mrosso, R. Miyagi, I. van der Sluijs, et al. 2008. Speciation through sensory drive in cichlid fish. Nature 455:620-626.

Servedio, M. R., and R. Bürger. 2014. The counterintuitive role of sexual selection in species maintenance and speciation. Proceedings of the National Academy of Sciences of the USA 111:8113-8118.

Smith, K. L., L. J. Harmon, L. P. Shoo, and J. Melville. 2011. Evidence of constrained phenotypic evolution in a cryptic species complex of agamid lizards. Evolution 65:976-992.

Streelman, J. T., and P. D. Danley. 2003. The stages of vertebrate evolutionary radiation. Trends in Ecology and Evolution 18:126-131.

Stuart-Fox, D., and I. P. F. Owens. 2003. Species richness in agamid lizards: chance, body size, sexual selection or ecology? Journal of Evolutionary Biology 16:659-669.

Stuart-Fox, D. M., A. Mousalli, G. R. Johnston, and I. P. F. Owens. 2004 Evolution of color variation in dragon lizards: quantitative tests of the role of crypsis and local adaptation. Evolution 58:1549-1559.

Stuart-Fox, D. M., and T. J. Ord. 2004. Sexual selection, natural selection and the evolution of dimorphic coloration and ornamentation in agamid lizards. Proceedings of the Roval Society B: Biological Sciences 271:2249-2255.

Wagner, C. E., L. J. Harmon, and O. Seehausen. 2012. Ecological opportunity and sexual selection together predict adaptive radiation. Nature 487:366-370.

West-Eberhard, M. J. 1983. Sexual selection, social competition, and speciation. Quarterly Reviews in Biology 58:155-183.

Wilson, S., and G. Swan, eds. 2008. A complete guide to reptiles of Australia. 2nd ed. New Holland, Sydney.

Wollenberg, K. C., I. J. Wang, R. E. Glor, and J. B. Losos. 2013. Determinism in the diversification of Hispaniolan trunk ground anoles (Anolis cybotes species complex). Evolution 67:3175-3190.

Yoder, J. B., E. Clancey, S. Des Roches, J. M. Eastman, L. Gentry, W. Godsoe, T. J. Hagey, et al. 2010. Ecological opportunity and the origin of adaptive radiations. Journal of Evolutionary Biology 23:15811596.

Zerova, G. A., and V. R. Chkhkvadze. 1984. Review of Cenozoic lizards and snakes of the USSR. Isvestiya Akademii Nauk Gruzinskoi SSR Seriya Biologicheskaya 10:319-325.

Associate Editor: Scott J. Steppan Editor: Judith L. Bronstein 